\title{
Dissecting tocopherols content in maize (Zea mays L.), using two segregating populations and high-density single nucleotide polymorphism markers
}

Xu Shutu', Zhang Dalong ${ }^{1}$, Cai Ye ${ }^{1}$, Zhou Yi ${ }^{1}$, Trushar Shah², Farhan Ali, ${ }^{3,4}$ Li Qing ${ }^{1}$, Li Zhigang ${ }^{1}$, Wang Weidong ${ }^{1}$, Li Jiansheng ${ }^{1}$, Yang Xiaohong ${ }^{1}$ and Yan Jianbing ${ }^{3^{*}}$

\begin{abstract}
Background: Tocopherols, which are vitamin E compounds, play an important role in maintaining human health. Compared with other staple foods, maize grains contain high level of tocopherols.

Results: Two $F_{2}$ populations (K22/Cl7 and K22/Dan340, referred to as POP-1 and POP-2, respectively), which share a common parent (K22), were developed and genotyped using a GoldenGate assay containing 1,536 single nucleotide polymorphism (SNP) markers. An integrated genetic linkage map was constructed using 619 SNP markers, spanning a total of $1649.03 \mathrm{cM}$ of the maize genome with an average interval of $2.67 \mathrm{cM}$. Seventeen quantitative trait loci (QTLs) for all the traits were detected in the first map and 13 in the second. In these two maps, QTLs for different traits were localized to the same genomic regions and some were co-located with candidate genes in the tocopherol biosynthesis pathway. Single QTL was responsible for 3.03\% to 52.75\% of the phenotypic variation and the QTLs in sum explained $23.4 \%$ to $66.52 \%$ of the total phenotypic variation. A major QTL (qc5-1/qd5-1) affecting a-tocopherol (aT) was identified on chromosome 5 between the PZA03161.1 and PZA02068.1 in the POP-2. The QTL region was narrowed down from 18.7 Mb to 5.4 Mb by estimating the recombination using high-density markers of the QTL region. This allowed the identification of the candidate gene VTE4 which encodes $\gamma$-tocopherol methyltransferase, an enzyme that transforms $\gamma$-tocopherol ( $\gamma$ T)to aT.

Conclusions: These results demonstrate that a few QTLs with major effects and several QTLs with medium to minor effects might contribute to the natural variation of tocopherols in maize grain. The high-density markers will help to fine map and identify the QTLs with major effects even in the preliminary segregating populations. Furthermore, this study provides a simple guide line for the breeders to improve traits that minimize the risk of malnutrition, especially in developing countries.
\end{abstract}

Keywords: Maize, Tocopherols, QTL mapping

\footnotetext{
* Correspondence: yjianbing@mail.hzau.edu.cn

${ }^{3}$ National Key Laboratory of Crop Genetic Improvement, Huazhong

Agricultural University, Wuhan, Hubei 430070, China

Full list of author information is available at the end of the article
} 


\section{Background}

Vitamin $\mathrm{E}$ is the common name that describes eight naturally occurring compounds having tocopherol activity [1]. The eight compounds are lipid-soluble antioxidants with two distinct groups, tocopherols and tocotrienols. The two groups differ in the saturation of the side chain and vary in the number and location of methyl groups [2], and are classified according to the location of the methyl group: $\alpha$-tocopherol $(\alpha \mathrm{T}), \beta$-tocopherol $(\beta \mathrm{T})$, $\delta$-tocopherol $(\delta \mathrm{T}), \gamma$-tocopherol $(\gamma \mathrm{T}), \alpha$-tocotrienol, $\beta$ tocotrienol, $\delta$-tocotrienol and $\gamma$-tocotrienol [3,4]. Vitamin E plays an important role in plants development and can protect cell membranes from oxidation. Vitamin E can prevent oxidation of polyunsaturated fatty acid by absorbing the superfluous free radicals produced in the lipid peroxidation chain reaction $[5,6]$. This serves to remove the free radical intermediates, thereby preventing continuity of the oxidation reaction. Vitamin E can prevent several diseases in humans and other animals, such as cardiovascular disease, Alzheimer's disease, neurological disorders, cancer, cataracts, inflammatory diseases and age-related macular degeneration [1,7]. Food and nutrition guidelines recommend $15 \mathrm{mg} /$ day of vitamin $\mathrm{E}$ for both adults and teenagers [8]. Individuals in developed nations can easily fulfill their daily requirement of vitamin E, but vitamin E deficiency (VED) in the developing countries is more common in premature infants and elderly people [9]. Furthermore, VED that is not immediately treated can lead to other serious diseases such as muscle weakness, ataxia, blindness, dementia, and eventually spinocerebellar degeneration [9-12].
The tocopherol biosynthesis pathway has been well studied in the model plant - Arabidopsis (Figure 1) [4]. Several enzymes that participate in the biosynthetic pathway have been characterized and annotated in Arabidopsis and Synechocystis PCC6803 including 4-hydoxyphenylpyruvate dioxygenase (HPPD/PDS) [13,14], tocopherol cyclase (VTE1/SXD1) [15,16], homogentisic acid phytyltrasferase (VTE2/HPT)[17-20], 4-benzoquinol methyltransferase (VTE3)[21,22], tocopherol methyltransferase (VTE4/ $\gamma$-TMT) [23,24], and phytol kinase (VTE5) [25]. In Arabidopsis, the first step in the biosynthetic pathway is to form the - homogentisic acid (HGA) and phytyldiphosphate (PDP). HGA can be synthesized from 4hydroxyphenyl-pyruvate by HPPD/PDS and PDP can be translated from phytol by VTE5. Through the function of geranylgeranyl reductase (GGR), PDP can also be synthesized from geranylgeranyl diphosphate (GGPP), which is also a precursor for carotenoid and tocotrienol biosynthesis. The second step in the pathway involves forming the immediate precursor, 2-methyl-6-phytyl-1,4benzoqiunol (MBPQ) from HGA and PDP through VTE2/ HPT. Third, VTE3 translates MBPQ into 2, 3-dimethyl-5phytyl-1,4-benzoqiunol (DMBPQ), and then converts to $\gamma \mathrm{T}$. The last step involves the formation of different tocopherols using VTE1 and VTE4/ $\gamma$-TMT enzymes. Many of the genes involves in the tocopherol synthesis pathways are similar in different plants and have been cloned in several plants, such as tomato and rice [26-28].

In addition to several other quality traits (such as oil and carotenoid), tocopherol content has been a focus of modern agriculture and several QTLs for tocopherol content has been mapped in different plant species [29-

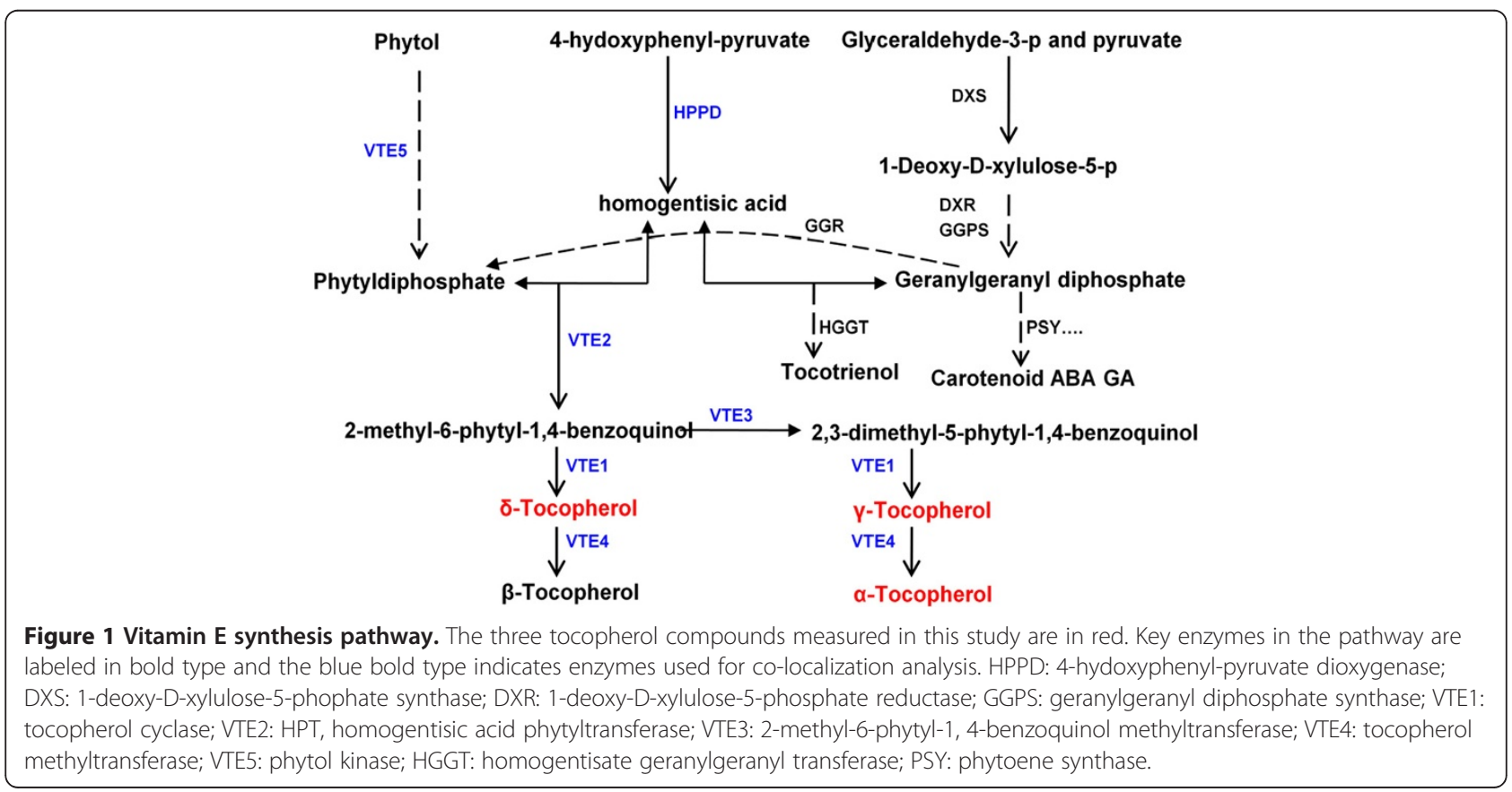


32]. Marwede et al. [29] used a double haploid (DH) population to locate several QTLs for $\gamma \mathrm{T}, \alpha \mathrm{T}$, TT and $\alpha /$ $\gamma$ in winter oilseed rape. Elsa $M$ and Vera-Ruiz et al. [30] performed fine mapping for the Tph1 gene, which can lead to a sharp reduction in $\beta T$ in sunflower $F_{2}$ and $F_{3}$ populations. To date, two maize QTL mapping studies of tocopherols have been conducted. Wong et al. [31] mapped several QTLs for tocopherols using an $\mathrm{F}_{2: 4}$ segregating population (W64a $\times$ A632) and one test-cross population with AE335 using 123 simple sequence repeat (SSR) markers, and identified QTLs for $\gamma \mathrm{T}, \alpha \mathrm{T}$, TT and $\alpha /$ $\gamma$ on chromosomes 1 and 5. Chander et al. [32] identified 31 QTLs in 16 regions covering all chromosomes except chromosome 4 by using a recombinant inbred line (RIL) population with 208 SSR markers. In these studies, the confident interval of identified QTLs was $>10 \mathrm{cM}$ because of the limited number of markers used.

Recently, a new genotyping technique, using the third generation marker system with SNP markers has been developed [33,34]. Compared with SSR markers, SNP markers are an ideal marker system because they are evenly distributed across the genome, are co-dominant, and accurate, and can be generated in a high-throughput and cost-effective manner. In this study, we used a maize GoldenGate assay containing 1536 SNPs to construct high-density linkage maps for two segregating populations with one common parent. The goals of this study were: (1) to identify QTLs affecting tocopherol content by analyzing two segregating populations with one common parent across the whole genome; (2) to fine map the major QTLs using the high-density markers; (3) and to explore the genetic architecture of tocopherol biosynthesis in different maize genetic backgrounds which could provide valuable information for further research.

\section{Results}

\section{Phenotypic variation in tocopherols}

Significant phenotypic variation was observed among the three parent lines in the traits of interest. For both $\gamma \mathrm{T}$ and TT, the content was lowest in the common parent K22 ( $\gamma \mathrm{T}: 3.95 \pm 0.15 \mu \mathrm{g} / \mathrm{g}$ and TT: $9.18 \pm 0.43 \mu \mathrm{g} / \mathrm{g}$ ), followed by CI7 ( $\gamma \mathrm{T}: 11.27 \pm 0.68 \mu \mathrm{g} / \mathrm{g}$ and TT: $18.09 \pm$ $1.06 \mu \mathrm{g} / \mathrm{g}$ ) and was highest Dan340 ( $\gamma \mathrm{T}: 31.46 \pm 0.42 \mu \mathrm{g} / \mathrm{g}$ and TT: $34.51 \pm 0.29 \mu \mathrm{g} / \mathrm{g})$. The $\alpha \mathrm{T}$ content was highest in CI7 $(6.76 \pm 0.65 \mu \mathrm{g} / \mathrm{g})$, followed by the common parent K22 $(5.13 \pm 0.29 \mu \mathrm{g} / \mathrm{g})$, and was lowest in Dan340 $(2.98 \pm 0.21 \mu \mathrm{g} / \mathrm{g})$ which contains half the $\alpha \mathrm{T}$ level of CI7. In contrast, $\alpha / \gamma$ ratio was highest in K22 (1.30 \pm $0.03)$, followed by CI7 $(0.60 \pm 0.0)$ and was lowest in Dan340 $(0.09 \pm 0.01)$. The distribution of different tocopherols in the three parents also varied. In K22, the content of $\gamma \mathrm{T}(3.95 \pm 0.15 \mu \mathrm{g} / \mathrm{g})$ was just half as that of $\alpha \mathrm{T}$ $(5.13 \pm 0.29 \mu \mathrm{g} / \mathrm{g})$ where as $\gamma \mathrm{T}$ content in $\mathrm{Cl} 7(11.27 \pm$ $0.68 \mu \mathrm{g} / \mathrm{g})$ was nearly twice as that of $\alpha \mathrm{T}(6.76 \pm 0.65 \mu \mathrm{g} / \mathrm{g})$, even in Dan340 $\gamma \mathrm{T}$ content $(31.46 \pm 0.42 \mu \mathrm{g} / \mathrm{g})$ was more than ten times as that of $\alpha \mathrm{T}(2.98 \pm 0.21 \mu \mathrm{g} / \mathrm{g})$ in Beijing location in 2009. And similar trends was also observed in Hainan location in 2009 (Table 1).

For different traits, the level of phenotypic variation varied by several folds ( $\alpha \mathrm{T}$ in POP-1) to nearly hundred folds $(\alpha / \gamma$ in POP-2) changes. The mean for $\gamma \mathrm{T}$ in POP$1(11.02 \pm 0.42 \mu \mathrm{g} / \mathrm{g})$ was less than that in POP-2 $(22.46 \pm$ $0.76 \mu \mathrm{g} / \mathrm{g}$ ) and the range was also larger in POP-2.the similar phenomenon was observed in TT. However the mean value for $\alpha \mathrm{T}$ and $\alpha / \gamma$ in POP-1 was higher than that in POP-2 and was also consistent with the observed value for the respective parents of each line (Table 1 ).

The broad sense heritability $\left(h^{2}\right)$ was estimated from the $\mathrm{F}_{2: 3}$ data and the two corresponding $\mathrm{F}_{2: 4}$ populations.

Table 1 Means, range, and broad-sense heritability $\left(h^{2}\right)$ for tocopherols related traits

\begin{tabular}{|c|c|c|c|c|c|c|c|c|c|c|}
\hline \multirow[t]{2}{*}{ Trait } & \multirow{2}{*}{$\begin{array}{c}\mathrm{K} 22^{\mathrm{a}} \\
\text { Mean } \pm \text { SE }\end{array}$} & \multirow{2}{*}{$\begin{array}{c}\mathrm{Cl}^{\mathrm{a}} \\
\text { Mean } \pm \mathrm{SE}\end{array}$} & \multirow{2}{*}{$\begin{array}{c}\text { D } \\
\text { Mean } \pm \text { SE }\end{array}$} & \multirow[t]{2}{*}{ Populations } & \multicolumn{3}{|c|}{$\mathrm{K} 22 / \mathrm{Cl} 7$ population } & \multicolumn{3}{|c|}{ K22/Dan340 population } \\
\hline & & & & & Mean \pm SE & range & $h^{2 \mathrm{~b}}$ & Mean \pm SE & Range & $h^{2 \mathrm{~b}}$ \\
\hline \multirow[t]{3}{*}{$\gamma^{\top}$} & $3.95 \pm 0.15$ & $11.27 \pm 0.68$ & $31.46 \pm 0.42$ & $09 \mathrm{BJF} \mathrm{F}_{2: 3}$ & $11.02 \pm 0.42$ & $1.96-45.81$ & 0.73 & $22.46 \pm 0.76$ & $2.70-66.28$ & 0.81 \\
\hline & - & 10.37 & 33.40 & $09 \mathrm{HNF}_{2: 4}$ & $10.96 \pm 0.56$ & $0.71-43.27$ & & $22.32 \pm 0.95$ & $1.35-54.78$ & \\
\hline & - & - & - & $10 \mathrm{HBF}_{2: 4}$ & $5.65 \pm 0.22$ & $1.42-17.95$ & & $12.12 \pm 0.62$ & $1.30-38.23$ & \\
\hline \multirow[t]{3}{*}{ aT } & $5.13 \pm 0.29$ & $6.76 \pm 0.65$ & $2.98 \pm 0.21$ & $09 \mathrm{BJF} F_{2: 3}$ & $8.24 \pm 0.21$ & $2.39-18.22$ & 0.77 & $6.63 \pm 0.22$ & $0.67-23.73$ & 0.59 \\
\hline & - & 14.95 & 5.57 & $09 \mathrm{HNF}_{2: 4}$ & $10.11 \pm 0.27$ & $1.88-19.93$ & & $6.66 \pm 0.26$ & $0.11-16.56$ & \\
\hline & - & - & - & $10 \mathrm{HBF}_{2: 4}$ & $12.11 \pm 0.3$ & $3.71-25.14$ & & $8.08 \pm 0.35$ & $0.93-34.10$ & \\
\hline \multirow[t]{3}{*}{$\pi$} & $9.18 \pm 0.43$ & $18.09 \pm 1.06$ & $34.51 \pm 0.29$ & $09 \mathrm{BJF} \mathrm{F}_{2: 3}$ & $19.24 \pm 0.52$ & $5.47-60.78$ & 0.75 & $29.32 \pm 0.78$ & $7.30-74.58$ & 0.79 \\
\hline & - & 25.32 & 38.97 & $09 \mathrm{HNF}_{2: 4}$ & $21.07 \pm 0.68$ & $4.11-60.43$ & & $29.16 \pm 0.92$ & $7.77-60.80$ & \\
\hline & - & - & - & $10 \mathrm{HBF}_{2: 4}$ & $17.75 \pm 0.44$ & $5.26-33.87$ & & $20.97 \pm 0.72$ & $3.65-51.53$ & \\
\hline \multirow[t]{3}{*}{$a / y$} & $1.30 \pm 0.03$ & $0.60 \pm 0.01$ & $0.09 \pm 0.01$ & $09 \mathrm{BJ} \mathrm{F}_{2: 3}$ & $0.94 \pm 0.04$ & $0.18-4.02$ & 0.70 & $0.41 \pm 0.02$ & $0.02-2.70$ & 0.68 \\
\hline & - & 1.44 & 0.17 & $09 \mathrm{HNF}_{2: 4}$ & $1.41 \pm 0.08$ & $0.07-5.83$ & & $0.63 \pm 0.07$ & $0.01-5.53$ & \\
\hline & - & - & - & $10 \mathrm{HBF}_{2: 4}$ & $2.61 \pm 0.08$ & $0.19-6.30$ & & $1.09 \pm 0.08$ & $0.05-5.31$ & \\
\hline
\end{tabular}

\footnotetext{
${ }^{a}$ Average of three repeats tocopherols contents of the three parents in 2009 Beijing; ${ }^{b}$ Broad-sense heritability of the tocopherols in the two populations; Note:
} The unit for $\gamma \mathrm{T}$, aT, and $\Pi \mathrm{T}$ is $\mu \mathrm{g} / \mathrm{g}$, the max contents for each trait were bold type. 
The heritability for each trait was high but varied for different traits. Heritability was highest $(0.81)$ for $\gamma \mathrm{T}$ in POP-2 and lowest (0.59) was divulged for $\alpha \mathrm{T}$ in POP-2 (Table 1). Pearson correlation coefficients for each trait in every generation showed that $\gamma \mathrm{T}$ was significantly positively correlated $(r=0.82-0.96)$ with the secondary trait-TT but showed little or even no correlated with $\alpha \mathrm{T}$ ( $r=$ (-0.07)-0.47) (Additional file 1: Table S1). The correlation coefficients between the $\mathrm{F}_{2: 3}$ populations and two $\mathrm{F}_{2: 4}$ populations ranged from 0.45 to 0.57 in POP- 1 and from 0.26 to 0.77 in POP-2 (Additional file 1: Table S2).

\section{Genetic linkage map}

Among 1536 SNPs, 468 markers were polymorphic in POP-1 and 357 markers in POP-2. After deleting markers that were located in the same position or were unlinked, only 429 (POP-1) and 344 (POP-2) markers were used for linkage map construction (Table 2). Because of the common parent K22, the two maps had many common markers whereas, 619 unique markers were used to construct a consensus map following the method of $\mathrm{Wu}$ et al. (Additional file 1: Figure S1) [35]. The POP-1 map covered a 1389.3-cM region, smaller than that of POP-2 1567.5-cM region. The average interval distance between two markers was shorter in POP-1 $(3.25 \mathrm{cM})$ than the POP-2 $(4.57 \mathrm{cM})$. The integrated map covered a much larger region $(1649.03 \mathrm{cM})$ than the two separate maps, with 619 SNP markers and a narrow interval distance of $2.67 \mathrm{cM}$ (Table 2).

\section{QTL mapping}

After 1,000 permutation tests, the threshold logarithm of odds (LOD) scores were defined as 3.7 whereas 17 QTLs were detected in the POP-1 $\mathrm{F}_{2: 3}$ and 13 QTLs in POP-2 $\mathrm{F}_{2: 3}$ (Tables 3 and 4). In the Hainan environment, only seven QTLs were detected in POP-1 $\mathrm{F}_{2: 4}$ and five in POP$2 \mathrm{~F}_{2: 4}$. In Hubei, ten putative QTLs were observed for POP-1 and 12 for POP-2 (Tables 3 and 4). Seven QTLs for each of the POP-1 and POP-2 populations were detected in at least two environments. The major QTLs were confirmed in the three environments for the respective maps. In both maps the total QTLs detected were 30 and including 17 in POP-1 and 13 in POP-2. Most of the detected QTLs showed additive effects rather than dominate effects.

Among the 17 QTLs in the POP- $1 \mathrm{~F}_{2: 3}, \gamma \mathrm{T}$ and $\alpha \mathrm{T}$ had four each, whereas TT had six and $\alpha / \gamma$ had three (Table 3). These QTLs were mainly located in 11 regions on different chromosomes, with one each on chromosomes 1, 6, 7 and 8, two on chromosome 2 and four on chromosome 5. No QTLs were detected on chromosomes 3, 4, 9 and 10. Each QTL explained from 3.88\% ( $\alpha \mathrm{T}$ on chromosome 1 ) to $29.63 \%$ ( $\alpha \mathrm{T}$ on chromosome 5) of the phenotypic variation. All the QTLs explained $37.59 \%(\gamma \mathrm{T}), 44.36 \%(\alpha \mathrm{T}), 51.73 \%(\mathrm{TT})$ and $23.40 \%(\alpha / \gamma)$ of the total phenotypic variation for each trait. Two QTLs with a $>7$ LOD were detected in the POP-1 map. The qc5-1 was between the markers PZA03161.1 and PZA02068.1 (134.1-159.7 cM in the POP-1 map) affecting the content of $\gamma \mathrm{T}, \alpha \mathrm{T}$, TT and $\alpha / \gamma$ it explained $5.37 \%$ to $29.63 \%$ of the total phenotypic variation for each trait. The other QTL, defined as qc5-2 were located between the markers PZA01327.1 and PHM1870.20 (55.1-76.7 $\mathrm{cM}$ in the POP-1 map), and affected the content of $\gamma \mathrm{T}$, $\alpha \mathrm{T}$, TT and $\alpha / \gamma$; it explained $6.11 \%$ to $26.51 \%$ of the phenotypic variation for each trait (Figure 2A). The K22 allele of $q c 5-1$ on the long arm of chromosome 5 was responsible for decreasing the content of $\alpha \mathrm{T}$, TT and $\alpha / \gamma$ and for increasing $\gamma \mathrm{T}$. While to $q c 5-2$ at the short arm of chromosome 5 , the favorable allele was from $\mathrm{CI} 7$ for $\gamma \mathrm{T}, \alpha \mathrm{T}, \mathrm{TT}$, and $\mathrm{K} 22$ for $\alpha / \gamma$ (Table 3).

The 13 putative QTLs in POP-2 $\mathrm{F}_{2: 3}$ were distributed as follows: four $(\gamma \mathrm{T})$, two $(\alpha \mathrm{T})$, four $(\mathrm{TT})$, three $(\alpha / \gamma)$ (Table 4). These QTLs were located in five regions on different chromosomes; five QTLs each on chromosome 1 and 5, and three QTLs on chromosome 8. Three regions were on

Table 2 Marker characteristics by chromosome for the two linkage maps and the consensus map

\begin{tabular}{|c|c|c|c|c|c|c|c|c|c|c|c|c|}
\hline Population & Description & chr1 & chr2 & chr3 & chr4 & chr5 & chr6 & chr7 & chr8 & chr9 & chr10 & $\mathrm{EL}^{\mathrm{a}}$ \\
\hline \multirow[t]{3}{*}{$\mathrm{K} 22 / \mathrm{Cl}$} & Number of markers & 55 & 39 & 48 & 45 & 55 & 45 & 37 & 44 & 36 & 25 & 429 \\
\hline & Length(cM) & 202.3 & 132 & 154.1 & 144.9 & 194.4 & 138.6 & 105.5 & 135.7 & 104.6 & 77.2 & 1389.3 \\
\hline & Average interval(cM) & 3.75 & 3.47 & 3.28 & 3.29 & 3.6 & 3.15 & 2.93 & 3.16 & 2.99 & 3.22 & 3.25 \\
\hline \multirow[t]{3}{*}{ K22/Dan340 } & Number of markers & 52 & 22 & 39 & 20 & 30 & 41 & 30 & 46 & 31 & 33 & 344 \\
\hline & Length (cM) & 249.7 & 170.7 & 162.8 & 137.7 & 154.5 & 140.2 & 143.2 & 166.5 & 130.7 & 111.5 & 1567.5 \\
\hline & Average of interval & 4.9 & 8.13 & 4.28 & 7.25 & 5.33 & 3.51 & 4.94 & 3.7 & 4.36 & 3.48 & 4.57 \\
\hline Common $^{b}$ & Number of markers & 17 & 10 & 19 & 13 & 15 & 23 & 10 & 18 & 19 & 10 & 154 \\
\hline \multirow[t]{3}{*}{ Consensus $^{c}$} & Number of markers & 90 & 51 & 68 & 52 & 70 & 63 & 57 & 72 & 48 & 48 & 619 \\
\hline & Length(cM) (cM) & 250.8 & 168 & 166.1 & 149 & 211.4 & 156.7 & 139.2 & 166.3 & 129.3 & 112.4 & 1649.03 \\
\hline & Average interval(cM) & 2.82 & 3.36 & 2.48 & 2.92 & 3.06 & 2.53 & 2.49 & 2.34 & 2.75 & 2.39 & 2.67 \\
\hline
\end{tabular}

${ }^{a}$ entire linkage; ${ }^{b}$ these markers exist in the two linkage maps; ${ }^{c}$ the linkage map through integrating the two linkage maps into one map with the same markers. 
Table 3 QTLs for tocopherols in K22/CI7 population and related candidate genes

\begin{tabular}{|c|c|c|c|c|c|c|c|c|c|c|c|c|}
\hline Trait & Populations & Chr & $\mathrm{QTL}^{\mathrm{a}}$ & $\mathrm{PK}^{\mathrm{b}}(\mathrm{cM})$ & Marker* interval & Genetic interval (cM) & Physical interval $^{c}(\mathrm{Mb})$ & LOD & $A^{d}$ & $D^{e}$ & $\mathrm{R}^{2 \mathrm{f}}(\%)$ & Candidate gene \\
\hline \multirow[t]{9}{*}{$\gamma^{\top}$} & \multirow[t]{4}{*}{$09 \mathrm{BJF}_{2: 3}$} & 2 & $q c 2-1$ & 25.91 & PZB00901.3-PZA03228.4 & $24.02-54.47$ & $9.4-20.1$ & 4.33 & -1.84 & -0.18 & 5.99 & \\
\hline & & 5 & $9 c 5-2$ & 67.6 & PZA01327.1-PHM16854.3 & $62.04-77.24$ & $15.1-35.3$ & 11.84 & -3.9 & 0.58 & 17.61 & \\
\hline & & 5 & $9 c 5-3$ & 183.2 & PHM3612.19-PHM13639.13 & 196.03-207.23 & 213.3-215.8 & 3.98 & 1.91 & -2.53 & 5.16 & \\
\hline & & 7 & $9 c 7-1$ & 43.5 & PZA03149.4-PZA02643.1 & $48.86-62.83$ & 108.8-134.1 & 6.12 & 2.85 & 0.37 & 8.83 & \\
\hline & \multirow[t]{2}{*}{$09 \mathrm{HNF}_{2: 4}$} & 5 & $9 c 5-4$ & 57.1 & PZA01371.1-PZA01327.1 & $43.04-62.04$ & $8.3-15.1$ & 4.97 & -2.81 & -0.68 & 11.01 & \\
\hline & & 5 & $9 c 5-5$ & 93.5 & PZA00067.10-PZA00148.3 & 109.1-115.8 & $145.9-164.7$ & 10.18 & -2.56 & -2.95 & 17.33 & \\
\hline & \multirow[t]{3}{*}{$10 \mathrm{HBF}_{2: 4}$} & 5 & $9 c 5-2$ & 67.6 & PZA01327.1-PHM16854.3 & $62.04-77.24$ & $15.1-35.3$ & 15.82 & -2.66 & 0.67 & 25.02 & \\
\hline & & 5 & $9 c 5-1$ & 159.7 & PZA03161.1-PZA00545.26 & $144.6-177.68$ & $186.4-207.7$ & 5.53 & 1.12 & 0.31 & 7.75 & VTE4 \\
\hline & & 6 & $q c 6-1$ & 6.81 & PHM15961.13-PZA03069.8 & $7.0-25.9$ & $9.5-83.0$ & 3.82 & -1.22 & 0.21 & 5.32 & \\
\hline \multirow[t]{9}{*}{ aT } & \multirow[t]{4}{*}{$09 \mathrm{BJF}_{2: 3}$} & 1 & ac1-1 & 75.4 & PHM2130.29-PHM1950.71 & 97.59-104.09 & $55.5-67.8$ & 3.97 & -1.05 & 0.79 & 3.88 & \\
\hline & & 5 & $9 c 5-2$ & 59.1 & PZA01327.1-PZB008669.4 & $62.04-74.57$ & $15.1-33.1$ & 5.3 & -1.18 & 0.23 & 6.19 & \\
\hline & & 5 & $q c 5-1$ & 150.8 & PZA00352.23-PZA02060.1 & $152.75-166.18$ & 191.6-203.2 & 24 & -2.23 & -0.08 & 29.63 & VTE4 \\
\hline & & 6 & $9 c 6-2$ & 77.6 & PZA02262.3-PZB01308.2 & $87.7-95.2$ & 134.9-144.6 & 4.66 & -0.79 & -0.29 & 4.66 & \\
\hline & \multirow[t]{2}{*}{$09 \mathrm{HNF}_{2: 4}$} & 5 & $9 c 5-2$ & 67.6 & PZA03226.3-PZA02207.1 & $67.14-79.77$ & $20.2-49.9$ & 4.13 & -1.57 & 0.11 & 6.11 & \\
\hline & & 5 & $9 c 5-1$ & 150.8 & PZA00352.23-PZA02060.1 & $152.75-166.18$ & $191.6-203.2$ & 12.26 & -2.49 & 0.35 & 20.06 & VTE4 \\
\hline & \multirow[t]{3}{*}{$10 \mathrm{HBF}_{2: 4}$} & 1 & $9 c 1-1$ & 66.1 & PZA00081.18-PZA03189.4 & $85.05-101.69$ & $45.5-64.2$ & 4.11 & -1.04 & -0.39 & 5.48 & \\
\hline & & 5 & $9 c 5-2$ & 69.1 & PZA01327.1-PHM16854.3 & $62.04-77.24$ & $15.1-35.3$ & 14.64 & -2.73 & -0.16 & 18.17 & \\
\hline & & 5 & $q c 5-1$ & 149.5 & PZA00352.23-PZA02060.1 & $152.75-166.18$ & $191.6-203.2$ & 7.87 & -1.85 & -0.16 & 9.84 & VTE4 \\
\hline \multirow[t]{8}{*}{$\Pi$} & \multirow[t]{6}{*}{$09 \mathrm{BJF}_{2: 3}$} & 1 & $9 c 1-1$ & 68.1 & PZA00081.18-PHM1932.51 & $85.05-118.11$ & $45.5-120$ & 5.27 & -3.2 & 1.85 & 7.07 & \\
\hline & & 2 & $a c 2-2$ & 20.91 & PHM12952.13-PZB00901.4 & $12.9-25.32$ & $4.9-9.4$ & 4.09 & -1.64 & -1.05 & 5.99 & \\
\hline & & 5 & $9 c 5-4$ & 54.1 & PZA01371.1-PZA01327.1 & $43.04-62.04$ & $8.3-15.1$ & 6.49 & -3.56 & 1.63 & 9.53 & \\
\hline & & 5 & $9 c 5-2$ & 67.6 & PZA02113.1-PHM13675.17 & $72.97-90.34$ & $31.0-67.5$ & 12.49 & -4.6 & 0.48 & 16.87 & \\
\hline & & 5 & $9 c 5-1$ & 150.8 & PZA00352.23-PZA02060.1 & $152.75-166.18$ & $191.6-203.2$ & 4.34 & -0.66 & -2.21 & 5.37 & VTE4 \\
\hline & & 7 & $9 c 7-1$ & 41.6 & PZA03149.4-PZA02643.1 & $48.86-62.83$ & $108.8-134.1$ & 5.31 & 2.61 & 1.11 & 6.9 & \\
\hline & $09 \mathrm{HNF}_{2: 4}$ & 5 & $9 c 5-2$ & 67.6 & PZA01327.1-PHM13675.17 & $62.04-90.34$ & $15.1-67.5$ & 14.89 & -7.05 & -0.89 & 26.51 & \\
\hline & $10 \mathrm{HBF}_{2: 4}$ & 5 & $9 c 5-2$ & 63.9 & PZA01327.1-PZA02207.1 & $62.04-79.77$ & $15.1-49.9$ & 11.24 & -5.35 & 0.93 & 15.47 & \\
\hline
\end{tabular}


Table 3 QTLs for tocopherols in $\mathbf{K 2 2 / C 1 7}$ population and related candidate genes (Continued)

\begin{tabular}{|c|c|c|c|c|c|c|c|c|c|c|c|c|}
\hline \multirow[t]{8}{*}{$a / \gamma$} & \multirow[t]{3}{*}{$09 \mathrm{BJF} F_{2: 3}$} & 5 & $9 c 5-2$ & 57.1 & PZA01327.1-PHM2769.43 & $62.04-83.27$ & $15.1-58.5$ & 6.79 & 0.28 & -0.08 & 9.17 & \\
\hline & & 6 & $q c 6-2$ & 59.2 & PZA01729.1-PZA02328.5 & $60.5-76.8$ & $123.7-137.1$ & 4.85 & -0.23 & 0.17 & 8.72 & \\
\hline & & 8 & $q c 8-1$ & 69.9 & PHM934.19-PZA02011.1 & $69.68-82.39$ & $118.2-141.6$ & 4.17 & -0.14 & -0.06 & 5.51 & \\
\hline & \multirow[t]{2}{*}{$09 \mathrm{HNF}_{2: 4}$} & 5 & $q c 5-2$ & 66 & PZA03298.1-PHM16854.3 & $68.87-77.24$ & $21.9-35.3$ & 5.75 & 0.54 & 0.12 & 10.67 & \\
\hline & & 5 & $q c 5-1$ & 145.5 & PZA02751.1-PZA02513.1 & $151.05-165.68$ & $190.7-203.3$ & 9.08 & -0.51 & -0.28 & 18.37 & VTE4 \\
\hline & \multirow[t]{3}{*}{$10 \mathrm{HBF}_{2: 4}$} & 5 & $9 c 5-2$ & 67.6 & PZA01327.1-PHM2769.43 & $62.04-83.27$ & $15.1-58.5$ & 10.52 & 0.74 & -0.25 & 12.65 & \\
\hline & & 5 & $q c 5-1$ & 159.7 & PZA00352.23-PZA02015.11 & $152.75-180.48$ & $191.6-208.3$ & 19.32 & -0.81 & -0.11 & 26.03 & VTE4 \\
\hline & & 6 & $q c 6-2$ & 67.5 & PZA00473.5-PZA02262.3 & $60.4-87.7$ & $124.1-134.9$ & 6.05 & -0.56 & 0.3 & 8.29 & \\
\hline
\end{tabular}

${ }^{a}$ the QTL name which were defined only in our research; ${ }^{b}$ the peak position with the highest LOD in the K22/CI7 map; ${ }^{c}$ the physical distance from the website (http://www.panzea.org/, B73_version 5a.60); ${ }^{d}$ additive effect of the corresponding QTL, $A ;{ }^{e}$ dominance effect of the corresponding QTL, $D ;{ }^{f}$ the ratio of phenotypic variance can be explained by the QTL; ${ }^{*}$ the physical position of these markers can be obtained from the website (http://www.panzea.org/, B73_version 5a.60);

Note: the effect of the alleles assumes that the favorable allele came from K22. 
Table 4 QTLs for tocopherols in K22/Dan340 population and related candidate genes

\begin{tabular}{|c|c|c|c|c|c|c|c|c|c|c|c|c|}
\hline Trait & Populations & Chr & $\mathrm{QTL}^{\mathrm{a}}$ & $\mathrm{PK}^{\mathrm{b}}(\mathrm{cM})$ & Marker* interval & Genetic interval (cM) & Physical interval $(\mathrm{Mb})$ & LOD & $A^{d}$ & $D^{e}$ & $\mathrm{R}^{2 f}(\%)$ & Candidate gene \\
\hline \multirow[t]{9}{*}{$\gamma^{\top}$} & $09 \mathrm{BJF} \mathrm{F}_{2: 3}$ & 1 & $9 d 1-2$ & 131 & PZA02750.3-PHM2187.34 & $119.28-127.7$ & $102.6-157.1$ & 4.52 & -3.88 & 1.29 & 3.03 & \\
\hline & & 1 & ad1-1 & 167 & PZA02117.1-PHM4926.16 & $165.46-179.76$ & $224.1-241.2$ & 34.95 & -11.16 & 3.86 & 30.81 & \\
\hline & & 5 & $9 d 5-1$ & 98.5 & PZA02751.1-PZA02068.1 & $151.05-169.78$ & $190.7-205.3$ & 15.05 & -6.08 & -0.15 & 12.06 & VTE4 \\
\hline & & 8 & qd8-1 & 81.6 & PZA02748.3-PZA02011.1 & $68.92-82.39$ & 118.7-141.6 & 6.5 & 4.44 & -0.31 & 4.44 & \\
\hline & $09 \mathrm{HNF}_{2: 4}$ & 1 & qd1-1 & 167 & PHM3690.23-PZB01647.1 & $158.46-174.76$ & $218.1-231.7$ & 13.1 & -10.53 & 2.7 & 23.5 & \\
\hline & $10 \mathrm{HBF}_{2: 4}$ & 1 & ad1-2 & 49.8 & PZA00887.1-PZA00358.12 & $38.74-49.57$ & 11.0-19.0 & 5.31 & -3.43 & 1.27 & 5.38 & \\
\hline & & 1 & ad1-1 & 164 & PHM3690.23-kip1.3 & $158.46-190.8$ & $218.1-256.5$ & 24.31 & -6.25 & 0.47 & 32.63 & \\
\hline & & 2 & $a d 2-1$ & 67.7 & PZA03228.4-PHM10404.8 & $54.47-70.52$ & $20.1-40.5$ & 3.79 & -1.82 & -0.5 & 4.06 & \\
\hline & & 5 & $q d 5-1$ & 98.5 & PZA03161.1-PZA01265.1 & $144.6-163.15$ & $186.5-202.0$ & 14.35 & -4.45 & -1.39 & 18.2 & VTE4 \\
\hline \multirow[t]{6}{*}{ aT } & $09 \mathrm{BJF}_{2: 3}$ & 5 & $9 d 5-1$ & 98.5 & PZA02751.1-PZA02068.1 & $151.05-169.78$ & $190.7-205.3$ & 21.88 & 3.58 & -0.17 & 52.75 & VTE4 \\
\hline & & 8 & ad8-1 & 75.4 & PZB00592.1-PHM4203.11 & $76.29-77.22$ & $125.3-134.9$ & 3.71 & -1.36 & 0.59 & 5.01 & \\
\hline & $09 \mathrm{HNF}_{2: 4}$ & 5 & $9 d 5-1$ & 96.5 & PZA02751.1-PZA02068.1 & $151.05-169.78$ & $190.7-205.3$ & 5.63 & 1.89 & 0.39 & 12.44 & VTE4 \\
\hline & $10 \mathrm{HBF}_{2: 4}$ & 1 & ad1-1 & 169 & PHM3690.23-kip1.3 & $158.46-190.8$ & $218.1-256.5$ & 7.3 & -2.35 & 0.68 & 11.08 & \\
\hline & & 5 & $9 d 5-1$ & 101 & PZA03161.1-PZA02068.1 & $144.6-169.78$ & $186.5-205.3$ & 21.76 & 3.93 & 0.87 & 39.09 & VTE4 \\
\hline & & 10 & ad10-1 & 30.1 & PZA01642.1-PZA00079.1 & $28.06-29.45$ & $14.6-18.9$ & 4.14 & 0.5 & -1.96 & 5.37 & \\
\hline \multirow[t]{8}{*}{$\pi$} & $09 \mathrm{BJF}_{2: 3}$ & 1 & ad1-3 & 106 & PZA02292.1-PZA01267.3 & $89.29-109.03$ & $51.3-77.2$ & 4.9 & -3.31 & -0.36 & 3.97 & \\
\hline & & 1 & ad1-1 & 167 & PHM3690.23-PZB01647.1 & $158.46-174.76$ & $218.1-231.7$ & 42.07 & -12.34 & 3.42 & 50.67 & \\
\hline & & 5 & $9 d 5-2$ & 85.3 & PZA01779.1-PZA00643.13 & 103.8-107.1 & $82.0-91.8$ & 6.16 & -2.22 & -2.63 & 5.66 & HPPD-5 \\
\hline & & 5 & $a d 5-1$ & 92.5 & PZA03161.1-PZA01265.1 & $144.6-163.15$ & $186.5-202.0$ & 7.54 & -3.29 & -1.53 & 6.22 & VTE4 \\
\hline & $09 \mathrm{HNF}_{2: 4}$ & 1 & ad1-1 & 167 & PHM3690.23-PZB01647.1 & $158.46-174.76$ & $218.1-231.7$ & 13.42 & -10.49 & 2.9 & 25.28 & \\
\hline & $10 \mathrm{HBF}_{2: 4}$ & 1 & ad1-4 & 49.8 & PZA00887.1-PZA00358.12 & $38.74-49.57$ & $11.0-19.0$ & 4.72 & -4.14 & 1.52 & 5.62 & \\
\hline & & 1 & ad1-1 & 164 & PHM3690.23-PZB01647.1 & $158.46-174.76$ & $218.1-231.7$ & 24.13 & -8.54 & 1.2 & 42.48 & \\
\hline & & 2 & $q d 2-1$ & 67.7 & PZA03228.4-PHM10404.8 & $54.47-70.52$ & $20.1-40.5$ & 3.74 & -2.95 & 0.69 & 4.71 & \\
\hline \multirow[t]{7}{*}{$a / y$} & $09 \mathrm{BJF} \mathrm{F}_{2: 3}$ & 1 & ad1-1 & 168 & PHM3690.23-PHM4926.16 & 158.46-179.76 & $218.1-241.2$ & 24.2 & 0.3 & -0.15 & 26.67 & \\
\hline & & 5 & $9 d 5-1$ & 101 & PZA02751.1-PZA02068.1 & $151.05-169.78$ & $190.7-205.3$ & 24.26 & 0.33 & -0.09 & 28.18 & VTE4 \\
\hline & & 8 & qd8-1 & 78.1 & PZB00592.1-LYCE.1 & $76.29-79.82$ & $125.3-138.8$ & 4.28 & -0.12 & -0.02 & 4.32 & \\
\hline & $09 \mathrm{HNF}_{2: 4}$ & 1 & ad1-1 & 167 & PHM3690.23-PZB01647.1 & $158.46-174.76$ & $218.1-231.7$ & 9.8 & 0.68 & -0.31 & 17.94 & \\
\hline & & 5 & $9 d 5-1$ & 98.5 & PZA02751.1-PZA02068.1 & 151.05-169.78 & $190.7-205.3$ & 5.47 & 0.59 & -0.31 & 10.56 & VTE4 \\
\hline & $10 \mathrm{HBF}_{2: 4}$ & 1 & ad1-1 & 166 & PHM3690.23-PZB01647.1 & $158.46-174.76$ & $218.1-231.7$ & 3.61 & 0.46 & -0.15 & 4.71 & \\
\hline & & 5 & $9 d 5-1$ & 98.5 & PZA03161.1-PZA02068.1 & $144.6-169.78$ & $186.5-205.3$ & 26.84 & 1.2 & -0.22 & 51 & VTE4 \\
\hline
\end{tabular}




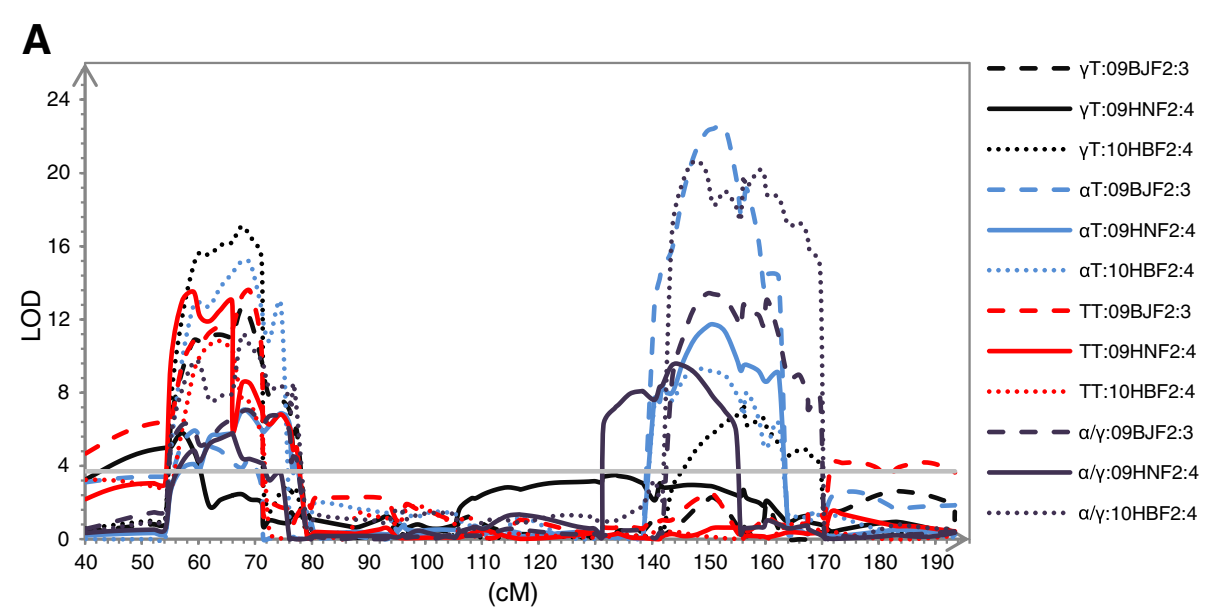

B

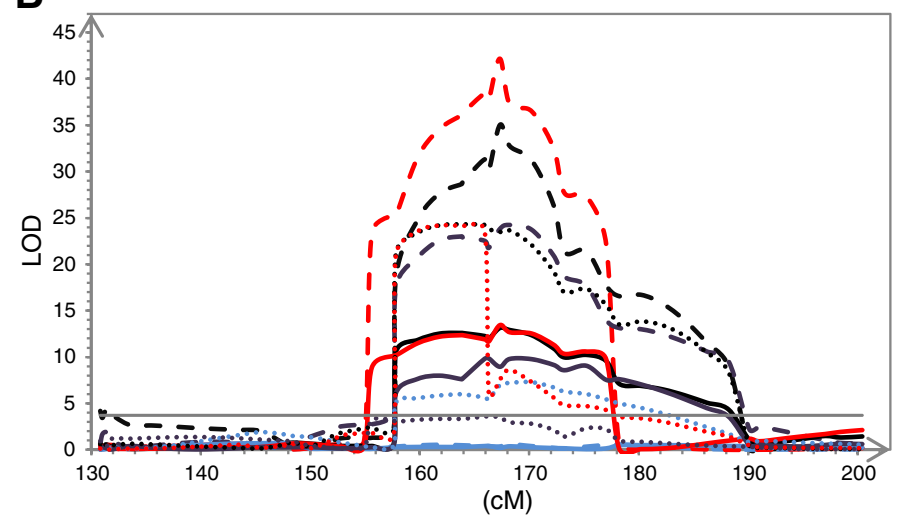

C

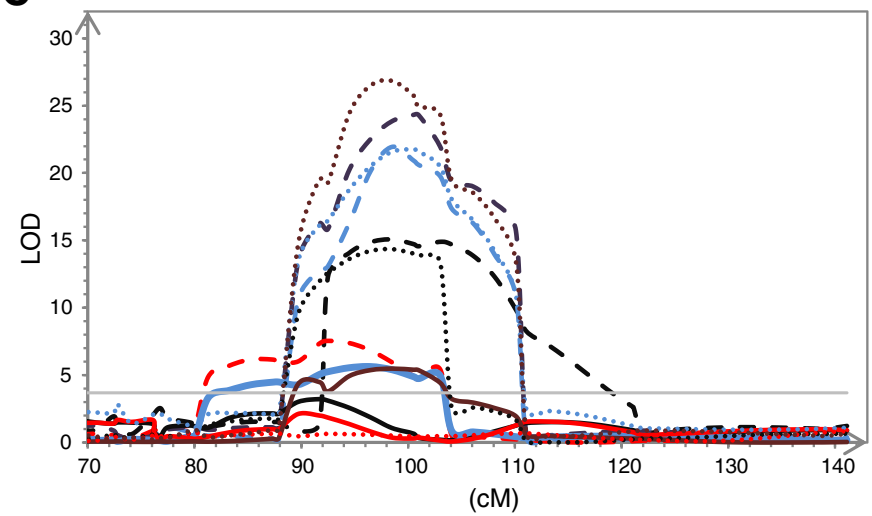

Figure 2 Distribution of major QTLs in the two maps (A), The two major QTLs on chromosome 5 in the POP-1 map (40-190 cM genetic distance); (B) The major QTL on chromosome 1 in the POP-2 map (130-200 cM genetic distance); (C) The major QTL on chromosome 5 in the POP-2 map (70 to $140 \mathrm{cM}$ genetic distance). The symbol color of relates to the corresponding trait in each location beside the figure. Gray solid lines indicated the permutated threshold.

chromosome 1, and one each on chromosome 5 and 8 . No QTL was observed on chromosomes 2, 3, 4, 6, 7, 9 and 10. Each QTL could explain the phenotypic variation from $3.03 \%$ ( $\gamma \mathrm{T}$ on chromosome 1 ; qd1-2) to $52.75 \%$ for $\alpha \mathrm{T}$ on chromosome 5 (qd5-1, between PZA03161.1 and PZA02068.1, 144.60 - 169.78 cM; Table 4). All detected QTLs could explain 50.34\% $(\gamma \mathrm{T}), 57.76 \%(\alpha \mathrm{T}), 66.52 \%(\mathrm{TT})$ and $59.17 \%(\alpha / \gamma)$ of the total variation for each trait. In POP-2 the $q d 1-1$ on chromosome 1 between PHM3690.23 and PHM4926.16 (158.5-179.76 cM in the POP-2 map) could explain $50.67 \%$ variation for $\mathrm{TT}$, -whereas $q d 5-1$ could explain $52.75 \%$ phenotypic variation for $\alpha \mathrm{T}$ (Table 4 , Figure $2 \mathrm{~B}$ and $\mathrm{C})$. The Dan340 alleles at qd1-1 were associated with increasing $\gamma \mathrm{T}, \alpha \mathrm{T}$ and TT contents but did not 
affect $\alpha / \gamma$, whereas the $q d 5-1$ alleles from K22 on the short arm of chromosome 5 , had increasing ( $\alpha \mathrm{T}$ and $\alpha / \gamma)$ or decreasing $(\gamma \mathrm{T}$ and TT) effects.

Fine mapping of $q d 5-1$ in the POP-2 map

To dissect the large $q c 5-1 / q d 5-1$ QTL detected in both maps, the polymorphic markers at the threshold LOD near the peak were selected. The QTL contributed 29.63\% $\left(09 \mathrm{BJF}_{2: 3}\right), 20.06 \%\left(09 \mathrm{HNF}_{2: 4}\right)$, and $9.84 \%\left(10 \mathrm{HBF}_{2: 4}\right)$ of the phenotypic variation for $\alpha \mathrm{T}$ in the POP-1, respectively. In POP-2 phenotypic variation of $52.75 \%\left(09 \mathrm{BJF} \mathrm{F}_{2: 3}\right)$, $12.44 \%\left(09 \mathrm{HNF}_{2: 4}\right)$ and $39.09 \%\left(10 \mathrm{HBF}_{2: 4}\right)$ for $\alpha \mathrm{T}$ were observed. The significant effects indicated that the qd5-1 QTL could be a qualitative gene and can be fine mapped by analyzing the recombinants among the segregating populations.

The POP-2 was first selected to analyze recombination within the $q d 5-1$ region because of its wide phenotypic variation for $\alpha \mathrm{T}$. From the initial mapping, the PZA03161.1 and PZA02058.1 markers were located at either end of the region separately by $25.2 \mathrm{cM}$ genetic distance and 18.7 Mb (186.4-205.1 Mb) physical distances. There were four additional markers within this region (Figure 3A). In total, five recombinant combinations were

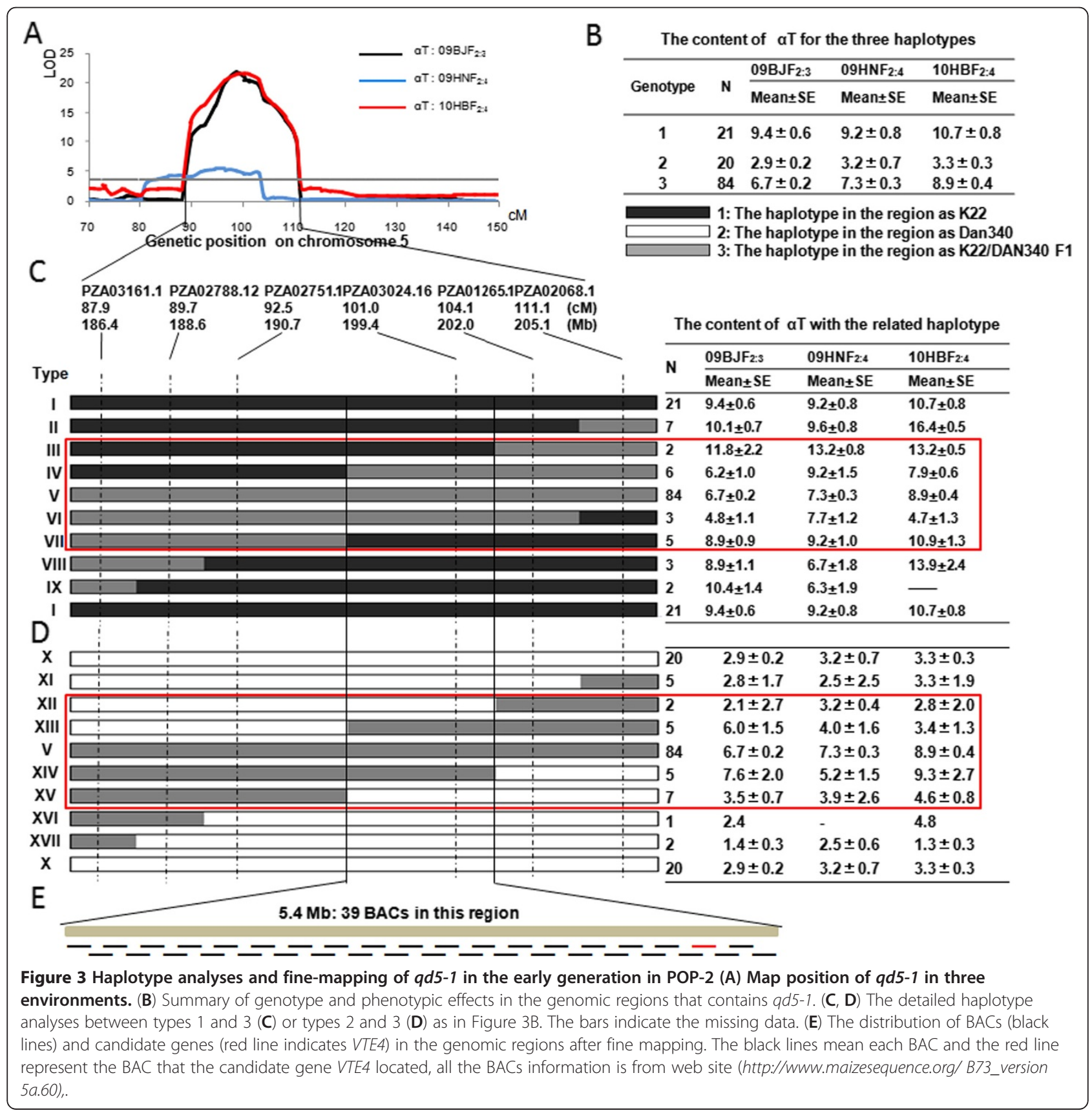


Table 5 Comparison of QTLs detected in this study and in the study of Chander's study

\begin{tabular}{|c|c|c|c|c|}
\hline \multirow[t]{2}{*}{ QTL_name } & \multirow{2}{*}{$\begin{array}{l}\text { Results described in this study } \\
\text { Position }\end{array}$} & \multicolumn{3}{|c|}{ Results from Chander et al. [32] } \\
\hline & & Trait & Position & Trait \\
\hline $9 c 1-1$ & $55.6-66.0 \mathrm{Mb}$ & $\mathrm{aT}, \mathrm{TT}$ & $51.5-69.7 \mathrm{Mb}$ & $a T, \gamma T, T T$ \\
\hline$q c 2-2$ & 4.9-9.4Mb & $\pi$ & $2.6-5.5 \mathrm{Mb}$ & $a T, \gamma T, T T$ \\
\hline$q c 5-1 / q d 5-1$ & $8.2-34.6 \mathrm{Mb}$ & $a T, \gamma T, T T$ & $12.0-33.0 \mathrm{Mb}$ & $\gamma T, T, a / \gamma$ \\
\hline$q c 6-1$ & $9.6-81.8 \mathrm{Mb}$ & $\gamma^{\top}$ & 77.7-95.0Mb & $\delta T$ \\
\hline qc7-1 & 103.4-128.4Mb & $\gamma T, T T$ & 85.0-134.0Mb & $\delta T$ \\
\hline
\end{tabular}

identified, dividing the 180 RILs (after deleting some ambiguous RILs) into 17 haplotypes (Figure $3 \mathrm{C}$ and D). The 17 haplotypes could be divided into 3 obvious groups based on $09 \mathrm{BJF}_{2: 3}$ data: group 1 for haplotypes IV, V, VI, XIII, and XIV (Figure 3C; $4.8-7.6 \mathrm{ug} / \mathrm{g}, \alpha \mathrm{T}$ ), group 2 for haplotypes I, II, III, VII, VIII and IV $(8.9-11.8 \mathrm{ug} / \mathrm{g}, \alpha \mathrm{T})$ and group 3 for the rest haplotypes $(-1.4-2.9 \mathrm{ug} / \mathrm{g}, \alpha \mathrm{T})$. Similar trends were also observed in the $\mathrm{F}_{2: 4}$ populations from the other two locations (Figure $3 \mathrm{C}$ and D). Comparing the phenotypes of type 1 (haplotype I from the parent K22 I in Figure 3C), type 3 (haplotype V from the K22/ Dan340 F1 in Figure 3C) and type 2 (haplotype X from the parent Dan340; Figure 3C) indicated that the parent K22 had the favorable allele for $\alpha \mathrm{T}$ in the QTL region (Figure 3B). The phenotype of group 1 was similar to type 3 , the group 2 was similar with type 1 and group 3 phenotype was similar with type 2 . Based on this information, the QTL region was narrowed down between markers PZA02751.1 and PZA01265.1 to around 10.8 Mb region. There are 39 bacterial artificial chromosomes (BACs) identified within this target region and included an annotation for the VTE4 tocopherol biosynthesis gene.

Using the same approach, another QTL-qd1-1 in POP-2, which explained $30.81 \%$ of $\gamma \mathrm{T}$ content, was analyzed. All the families were divided into 19 haplotypes and the haplotypes of I, II, III. IX, X, XI, and XII had the lowest $\gamma \mathrm{T}$ content. Consistent with our expectation, the interval could narrowed from $21.2 \mathrm{cM}$ (23.1 Mb, 218.1-241.2Mb) to $\sim 6.5 \mathrm{cM}(\sim 5.2 \mathrm{Mb})$ in POP-2 map (Additional file 1: Figure S2).

\section{Discussion}

The genetic basis for tocopherol biosynthesis in maize grain

In the present study, 30 QTLs were detected in two $F_{2: 3}$ populations, with one to six QTLs for each trait. These QTLs can explain the phenotypic variation of each trait from $23.4 \%$ for $\alpha / \gamma$ in POP-1 to $66.5 \%$ for TT in POP-2. Two major QTLs (qc5-1 and $q c 5-2)$ that affect all four target traits were identified in POP-1. Both $q c 5-1$ and qc5-2 were located on chromosome 5 and explained a maximum phenotypic variation of $30 \%$ and $25 \%$ for $\alpha \mathrm{T}$, respectively (Table 3). In POP2, the major QTLs one (qd1-1) on chromosome 1 and the $q d 5-1$ QTL on chromosome 5 explained 51\% (TT) and53\% ( $\alpha \mathrm{T})$ phenotypic variation respectively (Table 4 ). More than $80 \%$ of the QTLs detected in this study contributed in an additive manner. Hence, vitamin $\mathrm{E}$ biosynthesis in maize grain may be controlled by several major and a number of minor QTLs. This phenomenon is different with other agronomic traits, such as flowering time [36] and leaf architecture [37]. These traits are controlled by many minor QTLs and to data no major QTLs have been reported. Vitamin $\mathrm{E}$ is beneficial for human and animal health, but the absence of a selection index makes it difficult to breed for this trait, which is not as important compared as other economic traits such as yield. This type of trait may not be under strong selection pressure in the breeding and farming community, which is why major QTLs were easily identified. With the advent of such major additive QTLs the total tocopherols content of maize grains can be easily increased using marker assistant selection (MAS), which can be a simple guide for breeders to improve such traits. Furthermore, fine mapping of these major QTLs will explore the phenomenon in a comprehensive way because only a few candidate genes were detected in each QTL region, which distinguishes this pathway in maize from the extensively studied corresponding one in Arabidopsis. Hence, the study of tocopherol compounds in maize grains will help to increase the economic and nutritional value of maize crops which could account for more than half of the increased worldwide consumer demand for cereals [38].

When a QTL with a large effect is identified, determining the causal gene is a tedious and time-consuming task [39], although the involvement of a few major genes, facilitates the identification and fine mapping of the candidate gene. In addition, a single large-effect QTL often has multiple, closely linked QTLs with smaller, and sometimes opposite, effects on the phenotype $[40,41]$. The $q c 5-1 / q d 5-1$ QTL has a large effect on the overall phenotype [31,32]. Table 5 shows some QTLs that were identified in previous study [32]. A comparison of the results shows that qd1-1 was only in POP-2, which is similar to the previous studies of chromosome 8 [32]. The populations used in this study are of different genetic background as compared with those in the 
previous studies, so the source may be different across the different genetic material. However, our analysis has resulted in better coverage of the maize genome by using a large number of markers to determine more possible QTLs playing any kind of major or minor role in this phenomenon.

It is interesting to note that the two candidate genes VTE4 and HPPD-5 from the tocopherol biosynthesis pathway were both located within one corresponding QTL region in this study, it suggested that the genetic system controlling the biosynthesis of tocopherol may be more complex in maize as compared with that in Arabidopsis. Hence, the tocopherol biosynthesis pathway should be explored in more maize populations with different genetic backgrounds. Further studies will also help to identify the exact number of QTLs with minor or major roles, as a large population size and high number of markers are required to provide a solid basis for further improvement. Finally, positional cloning of major QTLs is extremely important to validate the results described herein and to improve the overall performance of maize.

\section{Regulation of tocopherol synthesis}

Many biosynthetic genes control the rate of synthesis of tocopherol. Nine of the downstream genes have been thoroughly studied in Arabidopsis. VTE1, VTE2, VTE3, $V T E 4, V T E 5$ and HPPD are involved in the formation of the end-product, whereas GGPS, DXS, DXR and VTE5 are involved in synthesis of the tocopherol precursor (Figure 1). Maize homologous genes of the first six genes were identified through bioinformatics, with some genes having more than one copy in maize. The physical positions and abbreviated names of the enzyme and chromosome location of these candidate genes are given in B73 (Additional file 1: Table S3, http://www.maizesequence. org/, B73_version 5a.60).

Several QTLs co-localized with corresponding candidate genes, and just one QTL and candidate gene was found in more than one location (Tables 3 and 4). On chromosome 5, VTE4 were co-located in both maps, whereas HPPD-5 was found in only one population. The large QTL on chromosome 1 in POP-2 had no candidate gene, suggesting that the presence of additional unknown genes controlling tocopherol content have not been identified by comparative genomics.

\section{How to mine genes with large QTLs in the future}

The rapid development of the high-throughput SNP genotyping technique enables the easy construction of simple high-density linkage maps. In the present study, the linkage map constructed by SNP markers was 1389.3 $\mathrm{cM}$ in POP-1 and $1567.5 \mathrm{cM}$ in POP-2 with an average interval distance of 3.25 and $4.57 \mathrm{cM}$, respectively (average interval distance was $2.67 \mathrm{cM}$ in the consensus map). Previously, linkage maps were constructed by SSR markers with an interval distance of $10-30 \mathrm{cM}$ in maize and varying distance for different organism [42]. Highdensity maps more precisely localize major QTLs to smaller region.

Fine-mapping requires the construction of advanced backcrossing populations and high-density markers to narrow down the QTL region to one gene or even a single SNP [43]. Fine mapping and functional validation are usually more costly, laborious and time consuming. Recently, the rapid development of association mapping has enabled the identification of a single gene within a year of collecting phenotypic and genotypic data. It provides a new tool for analyzing quantitative traits. Li et al. [44] combined traditional fine mapping and association mapping to identify the functional gene fatb and validated the functional sequence variation using in vivo gene expression profiling and in vitro complementation studies. They developed markers based on the predicted gene sequences and increased marker density to narrow down the region of interest, and also performed an association analysis with these markers in 74 lines. The combined linkage and association mapping is therefore a beneficial tool for identifying novel genes for different qualitative and quantitative traits [44].

We performed fine mapping for the large $q d 5-1$ and qd1-1 by haplotype analysis in an early generation and obtained good results without constructing a large backcross population. This method allowed the large QTL qd5-1 region to be narrowed from $18.7 \mathrm{Mb}$ to $5.4 \mathrm{Mb}$, assuming that the recombination occurred in the middle of the markers. There were 39 BACs in this region, with VTE4 - GRMZM2G035213 found in BAC209363 using bioinformatic analysis (Figure 3E, http://www.maizesequence.org/, B73_version 5a.60). Recently, VTE4 was identified as the underlying gene of this QTL using genome-wide and candidate gene association analyses [45]. Two functional polymorphisms (InDel7 and InDel118) were significantly associated with $\alpha \mathrm{T}$. InDel7 segregates in the parents of the two populations. InDel118 segregates in K22 and Dan340 populations. Hence, CI7 has the best haplotype (7/118), DAN340 has the worst haplotype (0/0), and the haplotype of K22 (7/0) is intermediate, which is also consistent with the phenotype of the three parents and QTL effects in the two populations. The cloned gene VTE4 provides an excellent sample of the high-density markers for QTL fine mapping and cloning.

The size of the qd1-1, QTL diminished from 23.1 Mb to $2.6 \mathrm{Mb}$, and there were $22 \mathrm{BACs}$ in the $2.6 \mathrm{Mb}$ region without any known candidate genes (Additional file 1: Figure S2E). Further research is needed to validate the functional site of these QTLs. There might be more 
genes controlling the tocopherol degradation pathway than the genes known to be involved in the synthesis pathway. Hence, much more in-depth work is needed for dissecting the metabolic pathway of tocopherols in maize grain including the synthesis and degradation pathways.

\section{Conclusion}

This study identified different major QTLs in different populations compared with previous studies [32]. Thoroughly understanding the genetic architecture of tocopherol biosynthetic and degradation pathway is required to construct more populations with different genetic backgrounds. According to the recent methodology of combining linkage and association mapping [44], dissecting the tocopherol pathway can be performed in a short period of time with maximum validations, thus providing the scientific community with a base for MAS. MAS may be a useful and cost-effective tool for improving the nutritional value of the world's leading cereal. In the preceding decades many major QTLs for different traits were applied in breeding programs by developing some functional markers [46,47]. Similarly, the three major QTLs in this study (qd1-1, $q c 5-1 / q d 5-1$ and $q c 5-2)$ can provide a guide for the development of molecular markers for breeding program or further detailed and deep research.

\section{Methods}

\section{Genetic materials}

An elite Chinese inbred line K22 was chosen to cross with two other elite lines, CI7 and Dan340, which have significantly different tocopherol contents [48]. Four hundred kernels of each $\mathrm{F}_{2}$ population were planted to develop the $F_{2: 3}$ population by self-pollinating at the Changping experiment field of China Agricultural University in Beijing (spring, 2009). Thirteen individuals were grown in a 3 -meters row with 0.5 -meter spacing within the row. Ears were harvested after 40-45 days of pollination, and $237 \mathrm{~F}_{2: 3}$ families of POP-1 and $218 \mathrm{~F}_{2: 3}$ families of POP-2 were obtained and phenotyped, diseased and contaminated ears were excluded from analysis. These $\mathrm{F}_{2: 3}$ families were used for phenotyping and validation in offspring. Trials were conducted at two locations with two replications per location. At one location, the $F_{2: 3}$ families were planted in the Nanbin farm in Yacheng of Hainan province with 11 plants in each 3meters row (winter, 2009). Another trial was carried out in Hubei Academy of Agricultural Sciences with the same field design as that in Beijing in 2009 (spring, 2010). Pooled pollen from the line was used to pollinate at least five plants so as to harvest good ears for phenotyping. Finally, 189 (POP-1) and 198 (POP-2) $\mathrm{F}_{2: 4}$ families were measured in Hainan, and 213 (POP-1) and 177
(POP-2) $\mathrm{F}_{2: 4}$ families were measured in Hubei because of asynchronized flowering and additional developmental problems.

\section{Reagents}

The standards for $\gamma \mathrm{T}, \alpha \mathrm{T}, \delta \mathrm{T}$ and other chromatographygrade chemicals were purchased from Sigma (St Louis, MO, USA) and all other chemicals from Beijing Chemical Reagent Factory (Sinopharm Group Chemical Reagent Co., Ltd, Beijing, China).

\section{Measurement of tocopherols}

At physiological maturity the ears were harvested and shelled manually, and a sample of 50 well performed was taken for phenotyping. These kernels were selected from the middle of each $\mathrm{F}_{2: 3}$ or $\mathrm{F}_{2: 4}$ ears, by bulkpollinated in each family, respectively. All the kernels used for phenotypic analysis were dried for 60 hours at $45^{\circ} \mathrm{C}$, kept in the dark at $4^{\circ} \mathrm{C}$ and ground into powder for tocopherol extraction and measurement. Tocopherols were extracted with the modified method as described in previous studies $[32,48,49]$. Three metabolites $\gamma \mathrm{T}, \alpha \mathrm{T}$ and $\delta \mathrm{T}$ were measured separately. In addition to $\alpha \mathrm{T}$ and $\gamma \mathrm{T}$, two derived traits, TT (the sum of $\gamma \mathrm{T}, \alpha \mathrm{T}$ and $\delta \mathrm{T}$ ) and $\alpha / \gamma$ (the ratio of $\alpha-/ \gamma$-tocopherol) were also calculated.

The tocopherol content was determined by high performance lipid chromatography (HPLC) as described $[32,48,49]$. External standard curves were constructed with eight serial dilutions and with repeats for each dilute $\left(R^{2} \geq 0.99\right)$. The three tocopherols $(\gamma \mathrm{T}, \alpha \mathrm{T}$ and $\delta \mathrm{T})$ were separated on a reverse-phase C30 column (YMC CT99S05-2546WT C30, $4.6 \mathrm{~nm} \times 25 \mathrm{~cm}, 5 \mu \mathrm{m}$; Waters) at $30^{\circ} \mathrm{C}$ at $1.8 \mathrm{ml} / \mathrm{min}$ for the mobile phase $(\mathrm{v} / \mathrm{v} / \mathrm{v}, 75: 20: 5$; acetonitrile/methanol/dichloromethane) by scanning at $295 \mathrm{~nm}$ without a reference wave and were identified by the retention time of the standards. The peak times for $\delta \mathrm{T}, \gamma \mathrm{T}$ and $\alpha \mathrm{T}$ were $4.56 \mathrm{~min}, 5.15 \mathrm{~min}$ and $6.07 \mathrm{~min}$, respectively. All phenotypic data were generated on ChemStation software (Agilent Technologies).

\section{Phenotypic data analysis}

The variance of traits and the correlation coefficients between traits were analyzed using the "PROC GLM" procedure of SAS 8.02 (SAS Institute 1999). The broad sense heritability was estimated as $h^{2}=\sigma_{\mathrm{g}}^{2} /\left(\sigma_{\mathrm{g}}^{2}+\sigma_{\mathrm{gy}}^{2}+\sigma_{\mathrm{e}}^{2} / \mathrm{y}\right)$ with SAS 8.02. Here, $\sigma_{\mathrm{g}}^{2}$ is the genetic variance, $\sigma_{\mathrm{gy}}^{2}$ is the interaction of genotype with year, $\sigma_{\mathrm{e}}^{2}$ is the residual error, and $\mathrm{y}$ is the number of years [50]. All the traits were analyzed with the same method.

\section{Genotyping and linkage map construction}

Genomic DNA was extracted from all $455 \mathrm{~F}_{2}$ single plants (237 lines of POP-1 and 218 lines of POP-2) and 
from their parental genotypes using the modified procedure of Murry and Thompson [51]. All the families and parents were genotyped using the GoldenGate assays (Illumina, San Diego, CA, USA) containing 1,536 SNPs [34]. The SNP genotyping was performed on an Illumina BeadStation 500G at Cornell University Life Sciences Core Laboratories Center using the protocol supported by Illumina Company [52]. The details of the SNP genotyping procedure and allele scoring have been described [34]. The data from polymorphic SNPs were used to construct a genetic linkage map using Mapmaker 3.0 for each population [53]. The threshold LOD score for the test of independence of marker pairs was set at 3.0, and the marker order with the highest LOD score was then selected. The Kosambi mapping function was used for calculating map distances. The two individual maps were then combined to form a consensus map using merge map [35].

\section{QTL analysis}

For QTL detection the whole genome was scanned using composite interval mapping (CIM) with $2 \mathrm{cM}$ scanning intervals between markers and a windows size of $10 \mathrm{cM}$. We used Model 6 in the Zmapqtl module of Wincartographer 2.5 [54]. The threshold LOD values for putative QTLs for tocopherol content and composition were estimated after 1,000 permutations at a significant level of $\mathrm{p}<0.05$ [55]. The number of marker cofactors for the background control was set by forward-backward stepwise regression with five controlling markers.

\section{Additional file}

Additional file 1: Table S1. Correlation coefficients of trait pairs for tocopherol related traits in two segregating populations in three environments. Table S2. Correlation coefficients of each trait among three locations. Table S3. List of candidate genes related to tocopherols in maize grains compared with that in Arabidopsis. Figure S1. The entire linkage map of chromosome 1-chromosome 10. Figure S2. Haplotype analyses and fine mapping of ad1-1 in the early generation of K22/ Dan340 segregation population A: Map position of ad1-1 in three environments, 2009 Beijing, 2009 Hainan and 2010 Hubei. B: Summary of genotype and phenotype in the genomic regions harboring ad1-1. C: The detailed haplotype analyses between type 1 and type 3 as Additional file 1: Figure S2B. The bar means the missing data. D: The detailed haplotype analyses between type 2 and type 3 as Additional file 1: Figure $\mathrm{S} 2 \mathrm{~B}$. The bar means the missing data. The bar means the missing data. E: The distribution of BACs and candidate genes in the genomic regions after fine mapping. The black lines mean each BAC. All the BACs information is from web site (http://www.maizesequence.org/i B73 RefGen_v2).

\section{Abbreviations}

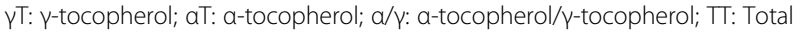
tocopherol; SSR: Simple sequence repeat; SNP: Single nucleotide polymorphism; QTL: Quantitative trait loci; POP-2: K22/Dan340 population; POP-1: K22/CI7 population; MAS: Marker assistant selection; LOD: Logarithm of odds; HPLC: High performance lipid chromatography; $h^{2}$ : The broad sense heritability; chr: Chromosome; 10HBF2:4: $\mathrm{F}_{2: 4}$ populations in Hubei 2010;
09HNF2:4: $F_{2: 4}$ populations in Hainan 2009; 09BJF2:3: $F_{2: 3}$ populations in Beijing 2009.

\section{Competing interests}

The authors declare no completing financial interests.

\section{Authors' contributions}

XST and ZDL prepared the materials; XST, ZDL LQ and CY performed the analyses of the genotype and phenotype; LZG and WWD participated to determine the phenotype; ST constructed the linkage maps; YJB, LSS and YXH designed the experiments and analyzed the chip raw data; XST, FA and YJB wrote the manuscript. All authors read and approved the final manuscript.

\section{Acknowledgements}

We would like to thank Abhishek Rathore for help with the construction of the linkage maps. We would also like to thank Santosh Deshpande and Weiwei Wen for their valuable comments in improving this manuscript. This research was supported by the National Hi-Tech Research and Development Program of China (2012AA10A307) and the National Natural Science Foundation of China (31222041).

\section{Author details}

'National Maize Improvement Center of China, China Agricultural University, Beijing 100193, China. ${ }^{2}$ Department of Bioinformatics, International Crops Research Institute for the Semi-Arid Tropics (ICRISAT), Hyderabad, India. ${ }^{3}$ National Key Laboratory of Crop Genetic Improvement, Huazhong Agricultural University, Wuhan, Hubei 430070, China. ${ }^{4}$ Cereal Crops Research Institute, Nowshera, Khyber Pukhtoonkhwa, Pakistan.

Received: 13 February 2012 Accepted: 30 October 2012

Published: 2 November 2012

\section{References}

1. Bramley PM, Elmadfa I, Kafatos A, Kelly FJ, Manios Y, Roxborough HE, Schuch W, Sheehy PJA, Wagner K-H: Critical reviews produced within the EU Concerted Action 'Nutritional enhancement of plant-based food in European trade' (Neodiet) - Vitamin E. Sci Food Agri 2000, 80:913-938.

2. Rocheford TR, Wong JC, Egesel CO, Lambert RJ: Enhancement of Vitamin E Levels in Corn. J Amer Coll Nutr 2002, 21:191-198.

3. Moss GP: Nomenclature of tocopherols and related compounds. Recommendations 1981. Eur J Biochem 1981, 123:473-475.

4. DellaPenna D: A decade of progress in understanding vitamin $E$ synthesis in plants. J Plant Physiol 2005, 162:729-737.

5. Traber MG, Atkinson J: Vitamin E, antioxidant and nothing more. Free Rad Biol \& Med 2007, 43(1):4-15.

6. Herrera E, Barbas C: Vitamin E: action, metabolism and perspectives. J Physio and Biochem 2001, 57(2):43-56.

7. Traber MG, Sies H: Vitamin in humans: demand and delivery. Annual Review Nutr 1996, 16:321-347.

8. Institute of Medicine: Food and Nutrition Board: Dietary reference intakes: Applications in dietary assessment. Washington, DC: National Academy Press; 2000:289.

9. Sokol RJ: Vitamin E deficiency and neurologic disease. Annual Review Nutr 1988, 8:351-373.

10. Aicardi J: Diseases of the nervous system in childhood. Mac Keith Press 1992, 108-202

11. Eggermont E: Recent advances in vitamin E metabolism and deficiency. Eur J Pediatr 2006, 165:429-434.

12. Muller DPR: Vitamin E and neurological function. Mol Nutr Food Res 2010 54:710-718.

13. Norris SR, Barrette TR, DellaPenna D: Genetic dissection of carotenoid synthesis in Arabidopsis defines plastoquinone as an essential component of phytoene desaturation. Plant Cell 1995, 7:2139-2149.

14. Norris SR, Shen XH, DellaPenna D: Complementation of the Arabidopsis pds1 mutation with the gene encoding phydroxyphenylpyruvate dioxygenase. Plant Physiol 1998, 117:1317-1323.

15. Porfirova S, Bergmüller E, Tropf S, Lemke R, Dörmann P: Isolation of an Arabidopsis mutant lacking vitamin $\mathrm{E}$ and identification of a cyclase essential for all tocopherol biosynthesis. Proc Natl Acad Sci. USA 2002, 99:12495-12500. 
16. Sattler SE, Cahoon EB, Coughlan SJ, DellaPenna D: Characterization of tocopherol cyclases from higher plants and cyanobacteria. Evolutionary implications for tocopherol synthesis and function. Plant Physiol 2003, 132:2184-2195.

17. Collakova E, DellaPenna D: Isolation and functional analysis of homogentisate phytyltransferase from Synechocystis sp. PCC 6803 and Arabidopsis. Plant Physiol 2001, 127:1113-1124.

18. Schledz M, Seidler A, Beyer P, Neuhaus G: A novel phytyltransferase from Synechocystis sp. PCC 6803 involved in tocopherol biosynthesis. FEBS Lett 2001, 499:15-20.

19. Savidge B, Weiss JD, Wong YHH, Lassner MW, Mitsky TA, Shewmaker CK, Post-Beittenmiller D, Valentin HE: Isolation and characterization of homogentisate phytyltransferase genes from Synechocystis sp. PCC 6803 and Arabidopsis. Plant Physiol 2002, 129:321-332.

20. Sattler SE, Gilliland LU, Magallanes-Lundback M, Pollard M, DellaPenna D: Vitamin $E$ is essential for seed longevity and for preventing lipid peroxidation during germination. Plant Cell 2004, 16:1419-1432.

21. Cheng Z, Sattler S, Maeda H, Sakuragi Y, Bryant DA, DellaPenna D: Highly divergent methyltransferases catalyze a conserved reaction in tocopherol and plastoquinone synthesis in cyanobacteria and photosynthetic eukaryotes. Plant Cell 2003, 15:2343-2356.

22. Motohashi R, Ito T, Kobayashi M, Taji T, Nagata N, Asami T, Yoshida S, Yamaguchi-Shinozaki K, Shinozaki K: Functional analysis of the $37 \mathrm{kDa}$ inner envelope membrane polypeptide in chloroplast biogenesis using a Ds-tagged Arabidopsis pale-green mutant. Plant J 2003, 34:719-731.

23. Shintani D, DellaPenna D: Elevating the vitamin E content of plants through metabolic engineering. Science 1998, 282:2098-2100.

24. Ischebeck T, Zbierzak AM, Kanwischer M, Dörmann P: A salvage pathway for phytol metabolism in Arabidopsis. J Biol Chem 2006, 281:2470-2477.

25. Valentin HE, Lincoln $\mathrm{K}$, Moshiri F, Jensen PK, Qi Q, Venkatesh TV, Karunanandaa B, Baszis R, Norris SR, Savidge B, Gruys KJ, Last RL: The Arabidopsis vitamin E pathway gene5-1 Mutant Reveals a Critical Role for Phytol Kinase in Seed Tocopherol Biosynthesis. Plant Cell 2006, 18:212-224.

26. Zou LP: Rice $\gamma$-tocopherol methyltransferase gene cloning and analysis of full-length cDNA. Hubei Agri Sci 2008, 47(11):1221-1224.

27. Zou LP: Cloning and sequence analysis $y$-tocopherol methyltransferase ( $y$-TMT) gene in tomato. J Anhui Agri Sci 2008, 36(2):437-439.

28. Shintani DK, Cheng ZG, DellaPenna D: The role of 2-methyl-6phytylbenzoquinone methyltransferase determining tocopherol composition in Synechocystis sp. PCC6803. FEBS Lett 2002, 511:1-5.

29. Marwede V, Gui MK, Becker HC, Ecke W: Mapping of QTL controlling tocopherol content in winter oilseed rape. Plant Breeding 2005, 124:20-26.

30. Vera-Ruiz EM, Velasco L, Leon AJ, Fernández-Martínez JM, Pérez-Vich B: Genetic mapping of the Tph1 gene controlling beta-tocopherol accumulation in sunflower seeds. Molecular Breeding 2006, 17:291-296.

31. Wong JC, Lambert RJ, Tadmor Y, Rocheford TR: QTL associated with accumulation of tocopherols in maize. Crop Sci 2003, 3:2257-2266.

32. Chander S, Guo YQ, Yang XH, Yan JB, Zhang YR, Song TM, Li JS: Genetic dissection of tocopherol content and composition in maize grain using quantitative trait loci analysis and the candidate gene approach. Mol Breeding 2008, 22:353-365.

33. Yan JB, Shah T, Warburton ML, Buckler ES, McMullen MD, Crouch JH: Genetic characterization and linkage disequilibrium estimation of a global maize collection using SNP markers. PLoS One 2009, 4(12):e8451.

34. Yan JB, Yang XH, Shah T, Sa'nchez-Villeda H, Li JS, Warburton ML, Zhou Y, Crouch JH, Xu YB: High-throughput SNP genotyping with the GoldenGate assay in maize. Mol Breeding 2010, 25:441-451.

35. Wu YH, Bhat PR, Close TJ, Lonardi S: On the Accurate Construction of Consensus Genetic Maps CSB 2008 - Computational Systems Bioinformatics Conference. Stanford, CA: http://alumni.cs.ucr.edu/ yonghui/mgmap.html.

36. Buckler ES, Holland JB, Bradbury PJ, Acharya CB, Brown PJ, Browne C, Ersoz E, Flint-Garcia S, Garcia A, Glaubitz JC, Goodman MM, Harjes C, Guill K, Kroon DE, Larsson S, Lepak NK, Li HH, Mitchell SE, Pressoir G, Peiffer JA, Rosas MO, Rocheford TR, Romay MC, Romero S, Salvo S, Villeda HS, Silva HS, Sun Q, Tian F, Upadyayula N, Ware D, Yates H, Yu JM, Zhang ZW, Kresovich S, Michael D, McMullen MD: The genetic architecture of maize flowering time. Science 2009, 325(5941):714-718.

37. Tian F, Bradbury PJ, Brown PJ, Hung H, Sun Q, Flint-Garcia S, Rocheford TR, McMullen MD, Holland JB, Buckler ES: Genome-wide association study of leaf architecture in the maize nested association mapping population. Nat Genet 2011, 43:159-162.

38. Yan JB, Warburton ML, Crouch J: Association mapping for enhancing maize genetic improvement. Crop Sci 2011, 51:433-449.

39. Ingvarsson PK, Street NR: Association genetics of complex traits in plant. New Phytol 2011, 189:909-922.

40. Doerge RW: Mapping and analysis of quantitative trait loci in experimental populations. Nat Rev Genets 2002, 3:43-52.

41. Mackay TFC, Stone EA, Ayroles JF: The genetics of quantitative traits: challenges and prospects. Nat Rev Genet 2009, 10:565-577.

42. Salvi S, Tuberosa R: To clone or not to clone plant QTLs, present and future challenges. Trends Plant Sci 2005, 10:297-304.

43. Remington DL, Thornsberry JM, Matsuoka Y, Wilson LM, Sherry R, Whitt SR, Doebley J, Kresovich S, Goodman MM, Buckler ES: Structure of linkage disequilibrium and phenotypic associations in the maize genome. Proc Natl Acad Sci 2001, 98:11479-11484.

44. Li L, Li L, Li Q, Yang XH, Zheng DB, Warburton ML, Chai YC, Zhang P, Guo $Y Q$, Yan JB, Li JS: An 11-bp Insertion in Zea mays fatb reduces the palmitic acid content of fatty acids in maize grain. PLoS One 2011, 6(9): e24699.

45. Li Q, Yang XH, Xu ST, Cai Y, Zhang DL, Han YJ, Li L, Zhang ZX, Gao SB, Li JS, Yan JB: Genome-wide association studies identified three independent polymorphisms associated with a-tocopherol content in maize kernels. PLoS One 2012, 7(5):e36807.

46. Cao SL: Development of application with marker assisted-selection in maize breeding. Crops 2008, 6:107-109.

47. Yang H, Yang JP, Rong TZ, Wang FG, Tan J, Qiu ZG: Developing the maize lines based on selections of phi116 and umc1044 markers which are resistant to sheath blight. Mol Plant Breeding 2007, 5(3):347-352.

48. Zhou Y, Fu ZY, Li Q, Xu ST, Chander S, Yang XH, Li JS, Yan JB: Comparative analysis of carotenoid and tocopherol compositions in high-oil and normal maize (Zea mays L.) inbreds. Acta Agronomica Sinica 2009, 35:2073-2084

49. Kurilich AC, Juvik JA: Quantification of carotenoid and tocopherol antioxidants in Zea mays. J Agric Food Chem 1999, 47:1948-1955.

50. Knapp SJ, Stroup WW, Ross WM: Exact confidence intervals for heritability on a progeny mean basis. Crop Science 1985, 25:192-194.

51. Murry MG, Thompson WF: Rapid isolation of high molecular weight plant DNA. Nucleic Acids Res 1980, 8:4321-4325.

52. Fan JB, Gunderson KL, Bibikova M, Yeakley JM, Chen J, Wickham Garcia E, Lebruska LL, Laurent M, Shen R, Barker D: Illumina universal bead arrays. Methods Enzymol 2006, 410:57-73.

53. Lincoln SE, Daly MJ, Lander ES: Construction genetic maps with MAPMAKER/ EXP 3.0. Whitehead Institute Technical Report, White-head Institute, Cambridge, Massachusetts. 3rd edition; 1993

54. Zeng ZB: Precision mapping of quantitative trait loci. Genetics 1994, 136:1457-1468.

55. Churchill GA, Doerge RW: Empirical threshold values for quantitative trait mapping. Genetics 1994, 138:963-971.

doi:10.1186/1471-2229-12-201

Cite this article as: Shutu et al:: Dissecting tocopherols content in maize (Zea mays L.), using two segregating populations and high-density single nucleotide polymorphism markers. BMC Plant Biology 2012 12:201.

\section{Submit your next manuscript to BioMed Central and take full advantage of:}

- Convenient online submission

- Thorough peer review

- No space constraints or color figure charges

- Immediate publication on acceptance

- Inclusion in PubMed, CAS, Scopus and Google Scholar

- Research which is freely available for redistribution 